Bol. Acad. peru. leng. 52. 2011 (69-89)

\title{
LA ENERGÍA NATIVA "EN BUSCA DE SU EXPRESIÓN": EL “PROCESO” DE JOSÉ CARLOS MARIÁTEGUI
}

\section{L'ENERGIE NATIVE “À LA RECHERCHE DE SON EXPRESSION”: LE “PROCÈS” DE JOSÉ CARLOS MARIÁTEGUI}

\section{THE NATIVE ENERGY “AFTER ITS EXPRESION": THE “PROCESS” OF JOSÉ CARLOS MARIÁTEGUI}

\author{
Vicente Cervera Salinas \\ María Dolores Adsuar Fernández \\ Universidad de Murcia. España
}

Resumen:

A partir de una propuesta de Pedro Henríquez Ureña, sobre el proceso cultural en Hispanoamérica, los autores procuran relacionar los postulados del intelectual dominicano con las proposiciones de José Carlos Mariátegui, que son enmarcadas en un proceso dialéctico de afirmación y negación, de continuidad y cambio, como ocurre con el modernismo respecto del romanticismo o de las tendencias de vanguardia frente al modernismo.

Résumé:

À partir d'une proposition de Pedro Henríquez Ureña, par rapport au procès cultural en Hispano Amérique, les auteurs essayent de mettre en relation les postulats de l'intellectuel dominicain avec les propositions de José Carlos Mariátegui qui sont encadrées dans un procès dialectique 
d'affirmation et négation, de continuité et changement, comme c'est le cas du modernisme en relation avec le romanticisme ou les tendances d'avant-garde face au modernisme.

\section{Abstract:}

Starting from a proposal of Pedro Henríquez Ureña, about the cultural process in Hispanic America, the authors seek to relate the Dominican intellectual postulates from the propositions of Jose Carlos Mariategui, that are framed in a dialectical process of affirmation and denial, of continuity and change, as it happen with modernism on the romanticism or the tendencies of vanguard against modernism.

Palabras clave:

Mariátegui; Henríquez Ureña; proceso cultural; Hispanoamérica.

Mots clés:

Mariátegui; Henriquez Ureña; procès cultural; Hispano Amérique.

Key words:

Mariátegui; Henríquez Ureña; cultural process; Hispanic America.

Fecha de recepción: $\quad$ 27/05/2011

Fecha de aceptación: $\quad 30 / 05 / 2011$

En 1928 se imprimía uno de los títulos axiales en la literatura hispanoamericana del siglo XX: Seis ensayos en busca de nuestra expresión de Pedro Henríquez Ureña. El primero de los seis comprendía una extensa reflexión titulada "El descontento y la promesa". Se trata de un texto que había sido pronunciado como una conferencia en la asociación Amigos del Arte de Buenos Aires, el 28 de agosto de 1926, según datación de Emma Sparatti Piñero en su edición de la Obra Crítica del dominicano ${ }^{1}$. Ya su título es factor indicativo del modelo de propuesta ensayística que contiene, pues refiere la polaridad que guía el devenir de la cultura de

1 Henríquez Ureña (2001. 1ª ed. 1960). 
https://doi.org/10.46744/bapl.201102.003

"nuestra América" en la primera mitad de la centuria, una vez cumplido el proceso de independencia política. En la estela de los grandes guías del pensamiento hispanoamericano del siglo XIX, Henríquez Ureña articula un binomio de conceptos polares donde el eco de las precedentes propuestas dualísticas sube un escalón hacia el reconocimiento de lo propio, pero también en pos de una superación de los limitaciones que impiden la consagración de la "promesa" que auspicia el autor a partir de su asimilación de la cultura hispanoamericana precedente: la civilización frente a la barbarie de Sarmiento; el "hombre natural" frente al "criollo exótico" o la "naturaleza" enfrentada a la "falsa erudición”, según José Martí y, al fin, la dialéctica entre los arquetipos de Ariel versus Calibán en el ensayo programático de José Enrique Rodó.

El planteamiento ideológico de Ureña incorporaba en la historia reflexiva sobre la identidad nacional un elemento trascendental en el tránsito ideológico: la comprensión irrecusable del componente desdeñado en el transcurso del tiempo como pieza necesaria para la evolución, como fase imprescindible en el tratamiento de toda historia cultural, dado el matiz revulsivo que toda generación arroja sobre los rescoldos que dejó la precedente. En una previsión de cierto materialismo histórico, o comprensión genuina de la historia como colisión de etapas en aras del surgimiento de una fusión final o síntesis armónica de consistencia utópica, hace gala el dominicano de una capacidad de abstracción ante el espectáculo de la sucesión de corrientes histórico-estéticas en la América hispánica, para generar tras su asentamiento un solar perpetuo y firme donde habrá de crecer el árbol nativo de elevación vertical y ahondamiento telúrico. Recordemos su propuesta: "El descontento provoca al fin la insurrección necesaria: la generación que escandalizó al vulgo bajo el modesto nombre de modernista se alza contra la pereza romántica y se impone severas y delicadas disciplinas (...)". Una vez superada esa fase de la contienda evolutiva, tras el previsible "descontento" que ocasionó la denodada insistencia en la propuesta modernista, surge de nuevo la llama de una "promesa" decidida: "Ahora, treinta años después hay $[. .$.$] en la$ América española juventudes inquietas, que se irritan contra sus mayores y ofrecen trabajar seriamente en busca de nuestra expresión genuina" (Henríquez Ureña 2001: 242-243). 
https://doi.org/10.46744/bapl.201102.003

Es en esta secuenciación contrastada de momentos axiales que forjan la historia "verdadera" de la América hispánica donde, por vez primera, se encuadra su esencia definitoria. Establecidos los patrones epistemológicos de su reconocimiento distintivo, los sucesivos intérpretes del alma "nuestra" americana quedarían capacitados para desarrollar sus contenidos desde otras perspectivas ideológicas o, cuando menos, desde posturas de afianzamiento de la piedra angular que Henríquez Ureña había depositado con solidez. En este sentido, la publicación de una obra clave en la historia del ensayismo hispanoamericano como fue Siete ensayos de interpretación de la realidad peruana de José Carlos Mariátegui, también en 1928, cabría ser leída en clave de inmediata respuesta y rearticulación de algunas propuestas trazadas en el texto de Henríquez Ureña. Ya la circunstancia de jugar con la numeración como propuesta en los títulos de ambas obras -el paso del seis al siete- permite establecer un juego dialéctico entre ellas, sin contar con el hecho de que el propio peruano plantea la remisión intertextual de modo explícito, dirigiendo guiños y evidenciando alusiones varias a la obra de Ureña. La cita inicial de la obra mariateguiana apunta un rasgo añadido de conexión, ya que recoge un pensamiento del filósofo alemán Friedrich Nietzsche, a quien Pedro Henríquez Ureña había declarado como uno de los focos de su formación intelectual, dedicándole incluso ensayos monográficos en su juventud. En 1908 había escrito en México "Nietzsche y el pragmatismo", texto que se incluiría más tarde en el volumen Horas de estudio (1910). Allí recordaba Ureña, con el filósofo alemán, que "lo que importa [...] no es que algo sea verdadero (en el sentido estático del intelectualismo), sino que se crea en que algo es verdadero: pensamiento que podría equipararse a la defensa que hacen del dogma ciertos católicos modernistas, singularmente Le Roy. «La dicha y la desgracia interior -dice Nieztsche en el aforismo 44 de La gaya ciencia - ha dependido de su fe en tal o cual motivo, no de que el motivo fuese verdadero. Esto último ha sido de interés secundario»" (Henríquez Ureña 2001: 76).

Por su parte, Mariátegui abre su colección de siete ensayos con una cita nietzscheana de la obra Der Wanderer und sein Schatten (El 
https://doi.org/10.46744/bapl.201102.003

paseante y su sombra), donde cabría reconocer un espíritu muy afín al que Henríquez Ureña recoge en su recreación de la figura "pragmática" del genio alemán. En lengua alemana, reproduce el peruano la reflexión del filósofo: "Ich will keinen Autor mehr lesen, dem man anmerkt, er wollte ein Buch machen; sondern nur jene, deren Gedanken unversehens ein Buch wurden". Es decir: "No quiero leer más al autor que me evidencie que quiere componer un libro, sino a aquél cuyos pensamientos de súbito se conviertan en un libro" (Mariátegui, 1976: 7). Mariátegui elogia, mediante el paratexto, la cualidad espontánea y reveladora que contiene la cita de Nietzsche: no se pondera tanto la producción programática de una "verdad", siguiendo postulados axiomáticos de estirpe kantiana, como podría ser la noción del "apriorismo" en la crítica del juicio. Frente a esas certezas de absoluta nitidez que revierten a propuestas donde la razón exhibe su talento para la construcción de universos "verdaderos", resplandece la fuerza de esa "verdad" revelada sin predisposición argumental, sin base metodológica, sin voluntad de consagración. Un pragmatismo que ama diversos matices donde la verdad se atomiza en verdades que dimanan siguiendo la dinámica de un "proceso" vivo, y no de un patrón prefigurado. Mariátegui se adscribe así a la "revolución" ideológica que había instaurado Henríquez Ureña en la intelectualidad hispanoamericana durante la primera década del siglo $\mathrm{XX}$, al introducir en la férrea pedagogía positivista del momento la savia renovadora del pensamiento modernista, pragmático, de raíz estética y contenido revulsivo. En este sentido, y a propósito de una distinción que el dominicano aporta en el ensayo "Caminos de nuestra historia literaria" (incluido como segundo de los Seis ensayos, aunque escrito en 1925), realiza el peruano un comentario que explicita su asimilación crítica. Según Mariátegui, "Henríquez Ureña dice que hay dos Américas: una buena y otra mala. Lo mismo se podría decir de Lima. Lima no tiene raíces en el pasado autóctono. Lima es la hija de la Conquista. Pero desde que, en la mentalidad y en el espíritu, cesa de ser solo española para volverse un poco cosmopolita, [...] deja de aparecer exclusivamente como la sede y el hogar del colonialismo y españolismo". La conclusión resulta coherente con los planteamientos sociales de su obra: "La nueva peruanidad es una cosa por crear" (Mariátegui 1976: 207). 
No resulta extraño que la crítica estampada por José Carlos Mariátegui un año más tarde, a partir de su lectura minuciosa de los Seis ensayos de Ureña, contenga uno de los más inteligentes elogios realizados sobre este texto. Mariátegui ensalza la combinación de "la disciplina y la mesura del crítico estudioso y erudito con la inquietud y la comprensión del animador que [...] alienta la esperanza y las tentativas de las generaciones jóvenes" (Mariátegui 2006: 255). Estima las cualidades del exégeta, su condición de investigador y sabio, con la vocación al magisterio que anima "el valor creativo y dinámico del impulso juvenil", convirtiendo en suma al ensayista en un emblema de la labor literariopedagógica de fuerte calado histórico y social, tan necesaria y valiosa para el desenvolvimiento de la cultura en los países hispanoamericanos ${ }^{2}$. El concepto de la crítica como salud -imprescindible para los pueblos- es otro de los rasgos más celebrados de la obra, y remite también a premisas martiana, tan excelentemente "transculturadas" por el poeta cubano a partir del espíritu libertador de Friedrich Nietzsche: "la crítica es salud", decretaba José Martí en Nuestra América, sin olvidar que "la solución está en crear" (Martí 2004: 164-165). La responsabilidad y el talento son las dotes preeminentes en la visión de conjunto que Mariátegui plasma a partir de los ensayos de Henríquez Ureña, y al indagar en las razones de tal caracterización destaca sin duda la particular atención que el peruano otorga al sentido ideológico-social de su obra.

Son años trascendentales en la biografía de Mariátegui, y centrales en la conformación de su ideario marxista, con todos los contraluces y claroscuros que tal caracterización comporta a la hora de consignar su naturaleza espiritual y ética. Recordemos que en 1926, tras su periplo

2 Para el Amauta, "Henríquez Ureña tiene las cualidades del humanista moderno, del crítico auténtico. Sus juicios no son nunca los del impresionista ni los del escolástico. La consistencia de su criterio literario, no es asequible sino al estudioso que al don innato del buen gusto une ese rumbo seguro, esa noción integral que confieren una educación y un espíritu filosóficos. Henríquez Ureña confirma y suscribe el principio de que la crítica literaria no es una cuestión de técnica o gusto, y de que será siempre ejercida, subsidiaria y superficialmente, por quien carezca de una concepción filosófica e histórica" (Mariátegui 2006: 256). El artículo original data del 28 de junio de 1929, y fue publicado en Lima en el diario Mundial. 
europeo y su conversión en figura capital del movimiento socialista peruano, edita la mítica revista izquierdista Amauta, que tendrá un seguimiento periódico hasta $1930^{3}$. Sería en octubre de 1928 cuando el Amauta decidiría fundar el Partido Socialista del Perú, concebido, según recuerda su biógrafo Eugenio Chang-Rodríguez, como "una mezcla de aprismo y comunismo" (Chang-Rodríguez 1983: 28). Interesa, en este sentido, comprobar cómo van incorporándose en los escritos mariateguianos de la primera mitad de la década de los veinte, progresiva y crecientemente, nociones y premisas correspondientes a planteos filosóficos marxistas: el peruano comienza a prestar atención singular a la necesidad de cooperación económica de las naciones hispanoamericanas y entiende que una de las causas de su dispersión específica procede de la inexistencia de comercio interno entre ellas, habiéndose convertido en suministradoras de materias primas y géneros alimenticios con países europeos o de los Estados Unidos. La cooperación, en cambio, ha sido suplantada por la "concurrencia", y tal disfunción en los acuerdos de intercambio económico les mantiene, en cierto modo, afianzadas en un modo de gestión anclada en el modelo colonial (Mariátegui 1960).

Este texto, titulado "La unidad de la América indo-española", fue publicado en la revista Variedades de Lima, en 1924 y estaría llamado a convertirse en un emblema del pensamiento anticapitalista de Hispanoamérica, hasta el punto de seguir siendo hoy en día un referente para los debates post-coloniales y la crítica al sistema de estructura y financiación económica que pasó al Nuevo Mundo bajo la égida

3 "Su casa volvió a convertirse en el centro de reunión de los intelectuales y artistas de vanguardia. Estudiantes y obreros de las universidades populares acudían a escuchar al nuevo orientador. En 1925 la Federación de Estudiantes le propuso para que ocupara una de los cátedras de San Marcos, pero, como Mariátegui ha escrito, la mala voluntad del rector y su delicado estado de salud impidieron el progreso de la iniciativa [...]. De Europa había traído el proyecto de fundar una revista izquierdista que sirviera de tribuna de avanzada de las nuevas tesis aplicables al Perú y promoviera los ideales socialistas. Con este fin lanzó el primer número de Amauta, en septiembre de 1926 (...)" (Chang-Rodríguez 1983: 24-25). 
liberalista de los Estados Unidos ${ }^{4}$. Un año más tarde insistía el Amauta en el sentido axial de la economía, no ya solo para entender la situación "actual" del Perú -y, por extensión, de toda la América hispánica-, sino también para evaluar correctamente el "proceso histórico" vivido por las naciones que la componen. Decreta Mariátegui, en este tenor, que el gran movimiento de emancipación de las repúblicas hispanoamericanas durante el siglo XIX admite una lectura en clave económica, sin que ello haga decaer la interpretación romántica de la independencia. Argumenta que la conquista destruyó una forma de producción en las naciones indígenas, perpetuada con dificultad durante el coloniaje. La "raíz primaria de la revolución de la independencia" vendría auspiciada por la necesidad de remover un aparato socio-económico fallido y nunca suficientemente bien asentado, que habría pretendido ignorar, sin éxito total, el entramado complejo de la realidad americana. En esta línea de lectura de clara índole marxista, los postulados económicos también desentrañarían "la clave de todas las otras fases de la historia de la república", concluyendo en suma que "la actual economía, la actual sociedad peruana tienen el pecado original de la conquista. El pecado de haber nacido y haberse formado sin el indio y contra el indio" (Mariátegui 1970: 59-61). Como vemos, la raíz indigenista es la matriz de la que partiría la consideración panorámica de la historia del Perú, vista desde una perspectiva de conflictos económicos a partir del fenómeno traumático de la conquista, considerado ahora desde prismas del materialismo-histórico socialista ${ }^{5}$.

4 "Es cierto que estas jóvenes formaciones nacionales se encuentran desparramadas en un continente inmenso. Pero la economía es, en nuestro tiempo, más poderosa que el espacio. Sus hilos, sus nervios, suprimen o anulan las distancias. La exigüidad de las comunicaciones y los transportes es, en América indo-española, una consecuencia de la exigüidad de las relaciones económicas [...]. La América española se presenta prácticamente fraccionada, escindida, balcanizada. Sin embargo, su unidad no es una utopía, no es una abstracción (...)" (Mariátegui, 1960: 16).

5 "Por consiguiente, aun un criterio meramente especulativo debe complacerse del creciente favor de que goza en la nueva generación el materialismo histórico. Esta dirección ideológica sería fecunda aunque no sirviera sino para que la mentalidad peruana se adaptara a la percepción y a la comprensión del hecho económico" (Mariátegui, 1970: 60). 
"Pecado original": atrevido sintagma de raigambre judeo-cristiana que utiliza con toda su fuerza semántica el Amauta para mostrar la "perversión" ideológica que sacudió las "venas abiertas" del continente americano como fruto de la conquista y, sobre todo, como consecuencia de la sistematización del orden colonial en sus feudos. Una lectura en clave materialista-histórica que será desdeñada, desde su misma raíz metafórica, años más tarde por el ensayista argentino Héctor $\mathrm{H}$. Murena, al considerar que "lo económico, como cualquier otro elemento de orden sociológico, no basta para explicar el estado espiritual de América" (Murena 1965: 158), entendiendo que, en suma, "el predominio de lo económico no es una causa de la situación pecaminosa sino un atributo de ésta". Para Murena, por tanto, el "pecaminoso" caso americano halla su causa en las entretelas espirituales de su historia, en su incomparable ejemplo de una "desculturización" a que se vio sometido el espíritu humano en el tiempo, fraguando con ello "el más evidente escándalo histórico del que se tenga noción" ". Una lectura, la del argentino, que a pesar de desdecir el presupuesto materialista de la historia como método explicativo de los avatares y las modificaciones que ocasionan los fenómenos en su devenir, no deja de suponer una curiosa "resemantización" del sentido profundo que Mariátegui perseguía, al condecir en la preocupación por el tratamiento de la cultura en tanto expresión genuina de la idiosincrasia americana. Y es ahí donde el germen del pueblo y del nativismo resurge como condiciones para una visión diáfana de la historia, para un "proceso" de interpretación de la realidad.

6 "Los pueblos de Europa y Asia han ido historizándose y espiritualizaban sus tierras: se hallaban siempre a la misma altura que éstas, y a través de la constante interacción de hombres y tierras fueron forjándose las naciones, se articularon las palabras con que éstas forjaron lo universal. Desarrollándose a la par que sus tierras, no tuvieron oportunidad de percibir que éstas significaban una fatalidad [...]. Ay de América. Porque a pesar de que la conciencia histórica universal trate de encubrir el desdichado escándalo que ella constituye diciendo que los pueblos que la integran son "jóvenes", [...] lo cierto es que no hay nada más viejo o avejentado que esta América integrada por razas indígenas en vías de fusión total o de extinción, y por individuos de razas no originarias de América que en América han visto tornarse súbitamente inútil, caduco, senil, el espíritu que traían de sus comarcas originales" (Murena 1965: 168-169). 
De manera más o menos explícita asomaría así, nuevamente, la alusión del Amauta a quien consideró "crítico sagaz" y "extraño a todo interés polémico" (Mariátegui 1976: 220), referente ineludible para su revisión crítica de la "realidad" histórico-literaria del Perú: Pedro Henríquez Ureña. Y así, en el séptimo de sus ensayos exegéticos, el que monográficamente dedicó a la literatura y sus procesos, evalúa Mariátegui los aciertos hermenéuticos del dominicano, revisando las más excelsas páginas de los Seis ensayos en busca de nuestra expresión. En el epígrafe dedicado a José Santos Chocano, el Amauta asume con sagacidad la teoría de Ureña basada en la invalidación de los criterios geográficoclimatológicos como expresión genuina de los rasgos distintivos de una cultura y de una experiencia literaria. En efecto, en "Caminos de nuestra historia literaria" (el segundo de los seis ensayos del dominicano) desentraña el tópico de la exuberancia como resultante expresivo de una naturaleza tropical. Mariátegui aplaude tal dictamen: "Para Henríquez Ureña la teoría de la exuberancia americana es una teoría falsa. Esta literatura es menos exuberante de lo que parece. Se toma por exuberancia la verbosidad", pero "los casos de verbosidad no son imputables a la geografía ni al medio". En cambio, un factor clave en la constitución del carácter netamente peruano refutaría, a partir del planteamiento de Henríquez Ureña, las tesis sobre la sobreabundancia que activa la ecuación entre el paisaje y sus palabras, y este elemento no sería otro que el indígena. Así, "lo inkaico" -como gusta escribir al Amauta- "es fundamentalmente sobrio [...]. El indio esquematiza, estiliza las cosas con un sintetismo y un primitivismo hieráticos" (Mariátegui 1976: 220221). Retornamos, pues, a una fuente primordial, en cuyas aguas no dejaría de reflejarse el pensamiento humanista e integrador del "alma americana" que fuera Pedro Henríquez Ureña.

Volvamos nuestra vista, para confirmar este vínculo particular, a los Seis ensayos del dominicano. Detengámonos nuevamente en el primer ensayo, "El descontento y la promesa", un título que sin duda agradaría a José Carlos Mariátegui por las resonancias polares de opuesta significación que vendrían a representar la dualidad entre el peso de la historia y la necesidad de superar sus limitaciones, acrisolada por un inevitable temple de utopía. El epígrafe fundamental para instituir esta alianza 
https://doi.org/10.46744/bapl.201102.003

entre los dos ensayistas estaría asignado al concepto de "energía nativa", que Ureña estampa casi al final del ensayo, como previa al "ansia de perfección" y a ese "futuro" donde aísla la siembra de esa esperanza que escogió como título inequívoco para su exposición. Tras el repaso al "afán europeizante" que, al decir de Ureña, debería morigerarse por el mero conocimiento de la realidad cultural que define la colonización americana, el dominicano espeta como radiografía "nacionalista": "No solo escribimos el idioma de Castilla, sino que pertenecemos a la Romania, la familia románica que constituye todavía una comunidad, una unidad de cultura" (Henríquez Ureña 2001: 250). Mas, una vez confirmada la alianza románica de su legado, implementa la noción básica que supone todo un himno a la revisión del sustrato prehispánico que late en el barro y el humus del territorio americano: el concepto de "energía nativa". Así, mientras el despliegue románico desarrollado en Hispanoamérica determinaría las "formas de la cultura", a la "energía nativa" estaría encomendada la constitución del "carácter original" de sus pueblos. Como vemos, la terminología revela un fondo de retemblor romántico, muy matizado al cabo por la vigorización del componente popular que emerge en el testimonio del ensayo. Esto favorecería sin duda una lectura "mariateguiana" de Henríquez Ureña, al menos de los títulos encartados en esta importante etapa de su producción literaria. De esta forma lo plasma el ensayista:

"El compartido idioma no nos obliga a perdernos en la masa de un coro cuya dirección no está en nuestras manos: solo nos obliga a acendrar nuestra nota expresiva, a buscar el acento inconfundible. Del deseo de alcanzarlo y sostenerlo nace todo el rompecabezas de cien años de independencia proclamada" (Henríquez Ureña 2001: 251).

Otra vez nos reclama la atención el giro expresivo del autor con esos "cien años de independencia proclamada", que sin duda resonarán en la celebérrima novela de Gabriel García Márquez, con todo el peso de su descontento a modo de maleficio escrito, de condena sellada, y también con la anuencia de una promesa renovada, aun sin éxito, en cada una de las generaciones de la maldita casta. Sea como fuere, resultó inspirada 
la invención de Pedro Henríquez Ureña con su término acuñado, para facilitar la entrada en materia de un fondo incuestionable, que será revivido en gran parte de los autores, novelistas y teóricos de la literatura hispanoamericana a partir de los años cuarenta, desde Miguel Ángel Asturias y Alejo Carpentier hasta Jorge Icaza y José María Arguedas?. La así denominada "energía nativa" funcionaría, en la imaginación del dominicano, en tanto magma fundador del carácter distintivo que se manifiesta en la verdadera esencia artística hispanoamericana. Sin él, los temas, las formas, los estilos y atributos que pautan su cronología carecerían del impulso auténtico, del fondo sustantivo y sustancial, como si del ADN de una cultura, o de un crisol de culturas, se tratara. La energía nativa es aquella pulsión biológica que marca el ritmo de un latido, el tono de una melodía, la entonación de una frase, el timbre de un argumento o de una descripción, más allá de la forma que revista o de la estructura que componga. La energía nativa contamina, en suma, el acervo popular hispanoamericano, y de él emanan finalmente las expresiones artísticas, que lo incorporan y al mismo tiempo perpetúan de manera más o menos programática.

Su naturaleza cabría entroncarla filosóficamente con el concepto que barajaría Friedrich Nieztsche en sus primeros escritos filológicos, y que más tarde evolucionaría hacia otros derroteros visionarios: la noción del "genio" aplicado a un espíritu colectivo y siempre entendido como fuerza motriz que dimana en expresión cultural autóctona o "energía nativa". No de otro modo explica Eugen Fink el término nieztscheano en el contexto de su desarrollo especulativo: "El genio es un instrumento

7 Bien ilustrativo el caso de Arguedas al respecto, no solo por su "peruanidad", sino también por su sensibilización extrema ante la problemática que refieren estas páginas. En su ensayo "El indigenismo en el Perú" parte de la posición de Mariátegui para arribar a un examen histórico del fenómeno. Considera que "Mariátegui no disponía de información sobre la cultura indígena o india; no se la había estudiado ni él tuvo oportunidad ni tiempo para hacerlo; se conocía y es probable que aún en estos días se conozca mejor la cultura incaica, sobre la que existe una bibliografía cuantiosísima, que el modo de ser de la población campesina indígena actual". No obstante, reconoce Arguedas que "la revista Amauta instó a los escritores y artistas que tomaran el Perú como tema. Y así fue como se inició la corriente indigenista en las artes" (Arguedas 1995: 330-331). 
https://doi.org/10.46744/bapl.201102.003

del fondo creador de la vida, que ve reflejada su propia esencia en la creación artística. Sin esta inserción básica del genio en una tendencia cósmica, la concepción de Nietzsche acerca de la cultura sería inhumana

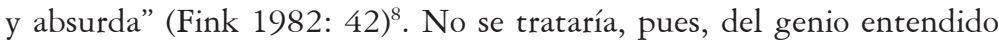
como individuación particular, sino como expresión colectiva que emana de ese surtidor ancestral y se dibuja en obras concretas, concebidas al fin por individuos determinados. La "energía nativa" de Henríquez Ureña representaría, paralelamente, ese entramado geológico fundido por la larga experiencia de los siglos, que produciría el acento cualitativo de una cultura popular, pero al mismo tiempo nutriría la labor concreta y la creación última de los artistas más relevantes desde el punto de vista nacional, es decir, de aquellos que habrían sentido el numen creador desde el fondo originario de la cultura, cuya esencia reactivarían con sus obras. No se trata, en suma, ni del individuo ni de la raza, sino del impulso que, prendido en el seno íntimo de una cultura, habla por boca del creador.

La aplicación del concepto de Henríquez Ureña reverberará de manera continuada, si bien no explícita, en ese séptimo ensayo mariateguiano que pretende interpretar la realidad peruana a partir del "proceso" particular a su literatura. Un repaso más o menos minucioso por sus páginas revela esta presencia fecunda en la obra central del peruano, propiciando de tal modo esa lectura del primero en clave materialistahistórica en que basamos este estudio. En ese "juicio" o "proceso" a la literatura, que el Amauta considera "abierto", su voz se alza como "testimonio de parte", y no se retrae al declarar sus intenciones en voz alta y con toda explicitud, explicando que aporta "a la exégesis literaria todas mis pasiones e ideas políticas", si bien y a pesar del "descrédito y degeneración de este vocablo en el lenguaje corriente", en su caso es la política "filosofía y religión" (Mariátegui 1976: 188). Consecuente con tales premisas, el analista no dudará en enunciar su "tabla de valores",

8 "El concepto de genio de Nietzsche, lo mismo que, más tarde, su concepto del superhombre," -explica Fink- "hay que entenderlos e interpretarlos, en última instancia, desde el servicio del hombre a la verdad. Verdad no significa aquí el conocimiento de las ciencias, sino la mirada que penetra en el fondo del mundo" (Fink 1982: 42). 
utilizada también de modo afín a como fuera promulgada por Henríquez Ureña en sus Seis ensayos. Y como base sustentadora de la misma, el peruano estimará el valor de las obras y los autores tributando especial relieve a aquellas manifestaciones donde prevalezca la huella, el eco o la semilla autóctona que participe de "energía nativa", aunque revista diversas modalidades y tipos de experiencia creadora.

Ya en su visión panorámica de la literatura colonial participa su juicio de este enfoque cuando se detiene con pormenor en la figura del Inca Garcilaso de la Vega, como "figura solitaria en la literatura de la Colonia", y en cuya obra "se dan la mano dos edades, dos culturas". Sin merma de tal consideración, subraya Mariátegui el carácter nativo de la crónica garcilasiana, al considerar que su caso "es más inka que conquistador, más quechua que español” (Mariátegui 1976: 193). El acento se declara consideración genérica sin ambages cuando el Amauta salta en su recorrido histórico hasta el siglo XIX. Antes de zambullirse en los autores de la República y sus diversos tonos literarios, propone su método de análisis, basado en dos propuestas fundamentales. La primera parte de una división en etapas, donde distingue tres momentos fundacionales ("un periodo colonial, un periodo cosmopolita, un periodo nacional”). Cabe señalar, al respecto, la curiosa inflexión histórica que supone el escalonamiento ascendente desde una fase cosmopolita a una de entonación nacional. Con ello pretende Mariátegui articular su concepto crítico ante la literatura que se instala en un cosmopolitismo sin raíz en lo propio. Consciente de que la apertura hacia las corrientes universales no pueden sino enriquecer el tejido tradicional (el cosmopolitismo fecunda la literatura colonial), es asimismo defensor de la superación última de este segundo estadio en una síntesis de la dialéctica, siguiendo modelos

9 "Hace falta poner en circulación tablas de valores: nombres centrales y libros de lectura indispensables. Dejar en la sombra populosa a los mediocres; dejar en la penumbra a aquellos cuya obra pudo haber sido magna, pero quedó a medio hacer: tragedia común en nuestra América [...]. La historia literaria de la América española debe escribirse alrededor de unos cuantos nombres centrales: Bello, Sarmiento, Montalvo, Martí, Darío, Rodó" (Henríquez Ureña 2001: 255). La "propedéutica" de Henríquez Ureña guiaría, así pues, los pasos en el camino, en el método, articulador de la historia que emprendió el Amauta. Cfr. Henríquez Ureña, Historia cultural y literaria de la América bispánica (Cervera 2007: lxv). 
teóricos e ideológicos de matriz hegeliana ${ }^{10}$. La literatura nacional, en suma, no sería la anulación de los periodos previos, sino su síntesis final, e ilustraría la superación ante una dialéctica insalvable entre lo colonial obsoleto y lo cosmopolita desarraigado. En la fase "nacional" las tendencias se equilibrarían, y en ella afloraría la "energía nativa" de los pueblos, aportando carácter específico y temperamento definido a las tendencias anteriores, donde se habría desatendido esta naturaleza. Declara, por ello, que "la literatura de un pueblo se alimenta y se apoya en su substractum económico y político", y explica en la misma línea cómo "la flaqueza, la anemia, la flacidez de nuestra literatura colonial y colonialista provienen de su falta de raíces". Se explaya el Amauta en torno a ese concepto capital, fértil para su proceso y su revisión de la historia: "El arte tiene necesidad de alimentarse de la savia de una tradición, de una historia, de un pueblo. Y en el Perú la literatura no ha brotado de la tradición, de la historia, del pueblo indígena. Nació de una importación de la literatura española; se nutrió luego de la imitación de la misma literatura". Ese carácter anémico, en fin, contamina el lado enfermo, carente de "energía", de la literatura durante el coloniaje: "Un enfermo cordón umbilical la ha mantenido unida a la Metrópoli” (Mariátegui 1976: 197). No queda, pues, a partir de esta explícita declaración sino corroborar los signos de su energía reactivada en los autores posteriores, algunos de la generación cosmopolita y, sobre todo, en los que participan de la literatura "nacional".

Interpreta, por ejemplo, Mariátegui que Ricardo Palma no puede ser incluido en la nómina de los escritores del colonialismo supérstite, a pesar de que esta tendencia quisiera anexarse su figura. Para el

10 Señala Eugenio Chang-Rodríguez en esta dirección: "Mariátegui no ciñe su análisis a la tradicional división europea en etapas neoclásica, romántica, modernista porque él prefiere emplear un andamiaje explicativo y ordenador según "una teoría moderna -literaria, no sociológica- sobre el proceso normal de la literatura de un pueblo". Mas al rechazar esquemas europeos, incluso el marxista, parece incurrir en una aparente contradicción: "Y no intentaré sistematizar este estudio conforme la clasificación marxista en literatura feudal o aristocrática, burguesa y proletaria". En vez de esos casilleros, Mariátegui distingue tres periodos: uno colonial, otro cosmopolita y otro periodo final que denomina nacional" (Chang-Rodríguez 1983: 138). 
Amauta, la calidad del creador de las Tradiciones peruanas lo aleja del servilismo retórico y su "latente rencor contra la aristocracia antañona y reaccionaria” lo acerca más a Manuel González Prada de lo que podría parecer a primera vista. De este último, como ejemplar supremo de la transposición del periodo colonial al cosmopolita, enfatiza la energía "nativa" que le condujo a producir la ruptura definitiva con el Virreinato (Mariátegui 1976: 203-208). En cuanto a Mariano Melgar, es presentado como el "primer expresador de categoría" del sentimiento indígena, de cuya savia no pudo nutrirse suficientemente la literatura peruano "por culpa de la hegemonía absoluta de Lima”. La raíz india, asimismo, se le antoja viva al Amauta en el "arte jaranero" de Alejandro Gamarra y desdeña, en cambio, la grandílocua vena externamente peruana, pero de raíz colonial y heredera del alma romántica española en el Alma América de José Santos Chocano. A José Gálvez le achaca, como historiador de la literatura, el centralismo limeño como expresión de la totalidad peruana y, en cambio, "malgrado su aristocratismo", ensalza la atracción que Abraham Valdelomar sintiera "por la gente humilde y sencilla", sospechando que, parejo a Oscar Wilde, "habría llegado a amar el socialismo". Conjetura, al fin, que su gran amigo y excelente poeta, creador del grupo "Colónida" y del poemario Confiteor, "reunía, elevadas a su máxima potencia, las cualidades y los defectos del mestizo costeño" (Mariátegui 1976: 236). Las cualidades de Valdelomar se afinan y escalonan al centrar su atención en José María Eguren, de quien aísla no tanto el nativismo cuanto la renuencia del poeta a la tradición morisca y romance de cuño hispano, por la veta gótica y los "aromas de leyenda" que supo apresar a partir de su fascinación por el mundo germánico y nórdico. Llega a decir de Eguren: "Es demasiado occidental y extranjero espiritualmente para asimilar el orientalismo indígena. Pero, igualmente, Eguren no comprende ni conoce tampoco la civilización capitalista, burguesa, occidental” (Mariátegui 1976: 247).

Y así, por la senda marcada con los hilos invisibles de la "energía nativa”, Mariátegui recorre paso a paso las etapas de su proceso, recalando en figuras como Alberto Hidalgo (Biografía de la palabra revolución), Alberto Guillén (Deucalión) o Magda Portal (El derecho de matar), centrando su atención en el caso excepcional de César Vallejo. 
Mariátegui, en este sentido, es el primer autor que revela y enfoca la excelsa y original expresividad lírica vallejiana desde instancias indigenistas, resaltando el acento peruano de su verso y dictaminando que "Vallejo tiene en su poesía el pesimismo del indio" (Mariátegui 1976: 256). La piedad humana latente en el lirismo de Los heraldos negros es atraída desde rincones étnicos, raciales y amparados en esa energía de progenie nativa que reconoce Mariátegui en los mejores autores encartados en su "proceso". Como muy bien señaló Eugenio Chang-Rodríguez, lo fundamental en la lectura que realiza el Amauta de Vallejo minusvalora los componentes simbolistas de su estilo para recalcar la "nota india" que penetra sus versos, modelando genuinamente sus poemas ${ }^{11}$. En conclusión, el proceso sobre la realidad literaria peruana cobra en el juicio de Mariátegui un claro enfoque indigenista, que alcanza en su visión "el sentido de una reivindicación de lo autóctono”, más allá de la función puramente sentimental que pudo tener el criollismo. Frente al regusto de idealización nostálgica presente en el colonialismo y neo-colonialismo a partir de la remota casta feudal de raigambre española, el indigenismo posee para el Amauta "raíces vivas en el presente", lo cual le permite cerrar su ensayo-crónica con una valoración del porvenir en dependencia de "la suerte del mestizaje" que asuman los pueblos hispanoamericanos.

Podría ser cierto que la perspectiva crítica de José Carlos Mariátegui derive hacia una doctrina de corte "eclectomarxista", como apuntan sus comentaristas ${ }^{12}$, integrada en un "ecumenismo crítico" de raíz materialista, pero que procuró adaptar sus fundamentos a la realidad americana y al sustrato ante-colonial de donde extrae su esencia

11 "Su análisis inteligente, agudo, pero hecho con apresuramiento periodístico, no reconoce otro indigenista hasta llegar a César Vallejo, en quien encuentra "por primera vez en nuestra literatura, sentimiento indígena virginalmente expresado»" (Chang-Rodríguez 1983: 173).

12 "Su aproximación eclectomarxista a la problemática literaria le llevó más allá del estricto análisis de la obra [...]. Es marxista cuando considera al arte como una superestructura económica condicionada por la lucha de clases y sujeta a la suerte de todas las mercancías [...]. Es ecléctico cuando, impulsado por sus constantes, hace suyas ideas heterodoxas opuestas al dogmatismo, a la autoridad arbitraria y a la supuesta infalibilidad de los pontífices de la inteligencia, del arte y de la política" (Chang-Rodríguez 1983: 201). 
distintiva. Pero, en cualquier caso, en Mariátegui "la interacción entre literatura y sociedad generadora de su interdependencia se fundamenta en la función ética intrínseca a la naturaleza de todas ellas" (ChangRodríguez 1983: 203). Y es en este punto donde, de nuevo, asoma la estela de un pensador tan aparentemente alejado de los presupuestos socialistas en sus "ensayos" de interpretación y búsqueda de expresión como lo fuera Pedro Henríquez Ureña. Su carácter integrador, ecléctico en el sentido más noble y filosófico del término, su marcada imparcialidad, justeza, equilibrio, mesura y ecuanimidad lo convierten no solo en el gran articulador de la utopía americana, sino también de la visión -en su momento, presente- y la figuración, futura, de una "patria de justicia", donde alentaría el latido libre de la raza cósmica americana. Más allá de los falsos estereotipos, Ureña declaró que la oposición entre la América mala y la buena no podría identificarse con la distinción geográfica y sus presumibles manifestaciones artísticas consecuentes, sino con la capacidad para la acción, el trabajo, el ansia de perfección, el arraigo de las instituciones de cultura y la erradicación de los vaivenes políticos. El hombre libre, con quien soñó Henríquez Ureña, solo podría habitar un solar donde la utopía tramontase la ilusión y hallara al fin su condición de profecía. El trabajo y la acción, presididos por el imperativo cultural del conocimiento de lo autóctono, serían los instrumentos medulares para su consecución:

"Nuestro ideal no será la obra de uno o dos o tres hombres de genio, sino de la cooperación sostenida, llena de fe, de muchos innumerables hombres modestos; de entre ellos surgirán, cuando los tiempos estén maduros para la acción decisiva, los espíritus directores; si la fortuna nos es propicia, sabremos descubrir en ellos los capitanes y timoneles, y echaremos al mar las naves" (Henríquez Ureña 2007: 432).

¿No perduran las intuiciones "sociales" y artísticas de Henríquez Ureña en la perspectiva crítica ante la realidad que hemos recorrido de la mano de José Carlos Mariátegui? Es difícil refutarlo. No olvidemos las aseveraciones que estampó en su reseña de 1929 sobre el libro capital de Henríquez Ureña: "Pedro Henríquez Ureña reconoce [...] 
la función de la "energía nativa". Más aún, la reivindica como factor primario de toda creación americana [...]. Y esta energía quizá en ningún americano actúa tanto como en los que pugnan por europeizar u occidentalizar América" (Mariátegui 2006: 257). El acento que el peruano insufla sobre el tema indigenista no resulta en este sentido tan alejado del universo filológico-historicista de Ureña, como cabe observar. Solo una "reivindicación de lo autóctono" adquiriría, para el Amauta, la validación última de un proceso donde la literatura respeta y calibra su naturaleza mestiza, proyectándola de modo variopinto en sus realizaciones prácticas. Pero esa raza mestiza, tal como es concebida por Mariátegui, no ha de acrisolarse en la especulación utopista de una "raza cósmica" imaginada en un futuro incierto. El mestizaje al que remite Mariátegui no es de patente filosófica, sino historiográfico y político. "La especulación del filósofo", declara, "no conoce límites de tiempo ni de espacio" (Mariátegui 1976: 279). Por ello, atiende de manera mucho más eficaz y rotunda a la enseñanza de quien buscó la "expresión americana" a través de las obras de su historia. Pedro Henríquez Ureña dejó su impronta de sabia erudición crítica en el alma peregrina del Amauta, y su celebrada invención de la "energía nativa" nos permite no solo comprender los Siete ensayos del peruano desde una óptica más abierta a una historiografía no tendenciosamente marxista, sino también - paralela e inversamente- recorrer sus Seis ensayos desde el prisma mariateguiano. Allí donde la patria de la justicia no tuviese que reivindicar su esencia natural, su nativa energía, nunca más sobre esta tierra. 


\section{BIBLIOGRAFÍA}

ARGUEDAS, José María (1995). "El indigenismo en el Perú". En Zea, Leopoldo: Fuentes de la cultura latinoamericana. México: F.C.E., pp. 325-338.

CHANG-RODRÍGUEZ, Eugenio (1983). Poética e ideología en José Carlos Mariátegui. Madrid: Porrúa.

HENRÍQUEZ UREÑA, Pedro (2001). Seis ensayos en busca de nuestra expresión. En Obra crítica. México: F.C.E., pp. 239-330.

HENRÍQUEZ UREÑA, Pedro (2007). Historia cultural y literaria de la América hispánica. Estudio preliminar de Vicente Cervera Salinas. Madrid: Verbum.

MARIÁTEGUI, José Carlos (1960). "La unidad de la América indoespañola". En: Temas de nuestra América, (= Obras Completas. vol. XII). Lima: Amauta.

MARIÁTEGUI, José Carlos (1966). Antología. Selección y prólogo de Benjamín Carrión. México: B. Costa-Amic.

MARIÁTEGUI, José Carlos (1970). "El hecho económico en la historia peruana”. En Peruanicemos al Perú. Lima: E.E. Amauta, pp. 58-61.

MARIÁTEGUI, José Carlos (1976). Siete ensayos de interpretación de la realidad peruana. Barcelona: Crítica-Grijalbo.

MARIÁTEGUI, José Carlos (2006). Literatura y estética. Caracas: Ayacucho.

MARTÍ, José (2004). Ensayos y crónicas. Madrid: Cátedra. 
LA ENERGía NATIVA “EN BUSCA DE SU EXPRESIÓN": EL “PROCESO”...

https://doi.org/10.46744/bapl.201102.003

MURENA, Héctor A. (1965). El pecado original de América. Buenos Aires: Sudamericana.

SKIRIUS, John (compilador) (2004). El ensayo hispanoamericano del siglo XX. México: F.C.E.

\section{Correspondencia:}

Vicente Cervera y María Dolores Adsuar

Docentes de la Universidad de Murcia (España).

Correo electrónico: vicente@um.es / adsuar@um.es 